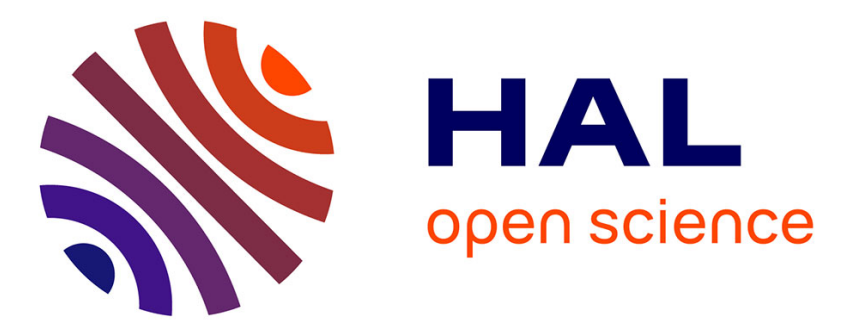

\title{
Numerical analyses of the sound transmission at low frequencies of a calibrated domestic wooden window
}

\author{
Chaïma Soussi, Mathieu Aucejo, Walid Larbi, Jean-François Deü
}

\section{To cite this version:}

Chaïma Soussi, Mathieu Aucejo, Walid Larbi, Jean-François Deü. Numerical analyses of the sound transmission at low frequencies of a calibrated domestic wooden window. Proceedings of the Institution of Mechanical Engineers, Part C: Journal of Mechanical Engineering Science, 2021, 235 (14), pp.26372650. 10.1177/09544062211003621 . hal-03225940

\section{HAL Id: hal-03225940 \\ https://hal.science/hal-03225940}

Submitted on 13 May 2021

HAL is a multi-disciplinary open access archive for the deposit and dissemination of scientific research documents, whether they are published or not. The documents may come from teaching and research institutions in France or abroad, or from public or private research centers.
L'archive ouverte pluridisciplinaire HAL, est destinée au dépôt et à la diffusion de documents scientifiques de niveau recherche, publiés ou non, émanant des établissements d'enseignement et de recherche français ou étrangers, des laboratoires publics ou privés. 


\title{
Numerical analyses of the sound transmission at low frequencies of a calibrated domestic wooden window
}

\author{
Chaima SOUSSI ${ }^{a}$, Mathieu AUCEJO ${ }^{\text {a }}$, Walid LARBI*a, Jean-François \\ DEÜa \\ ${ }^{a}$ Laboratoire de Mécanique des Structures et des Systèmes Couplés, \\ Conservatoire National des Arts et Métiers, \\ 2 rue Conté, 75003 Paris, France.
}

\begin{abstract}
This work focuses on the numerical prediction of the sound transmission of wooden windows in the low frequency range. In this context, the finite element method is used to solve the multiphysics problem. This choice is justified by the fact that this approach is suitable for the resolution of fluidstructure interaction problems in low frequencies, due in particular to its flexibility in taking into account the coupling between domains and the geometrical and material complexities of the structures. To reach the desired objective, experimental modal analyses of the main components of a window, and then of a complete one, are performed in order to calibrate the numerical models. Then, a configuration that combines free-fields on both sides of the structure is employed to evaluate the intrinsic acoustic response of the window. The numerical results for a symmetric and an asymmetric glazing are compared to experimental ones to evaluate the efficiency and validity of the developed models.
\end{abstract}

Keywords: vibro-acoustics of windows, transmission loss, experimental modal analysis, numerical model, finite element method, low frequency.

\section{Introduction}

In order to minimize the disturbances in buildings, it is essential to design facades having good acoustic performances. In general, building standards specify the minimum value for the apparent sound insulation value of the facade [1]. This indicator incorporates the contribution of all its components

\footnotetext{
*Corresponding author. E-mail address: walid.larbi@lecnam.net
} 
such as walls and windows. The acoustic performance of these components as well as their assembly influences the overall response of the façade. Nevertheless, the weaknesses in terms of acoustic insulation of a façade remain mainly air inlets, shutter boxes, glazed parts and windows [2, 3]. Unfortunately, for aesthetic reasons, large windows or even sections of glass walls are usually used in modern buildings [4]. Therefore, in order to have facades with satisfactory sound insulation, it is essential to know the acoustic performance of these elements.

Practically, the sound insulation of a building element is based on its sound transmission loss $(T L)$. The latter indicator is determined with experimental tests according to standards [5-8]. The tests are carried out in an acoustic laboratory using two finite-sized rooms and one or many loudspeakers to create the sound field excitation with the assumption that the flanking transmission is neglected. The standards assume that, in the two rooms, the sound field is perfectly diffuse which means that the energy density is the same on all points of the volume [9]. However, no diffuse field condition can be expected below the Schroeder frequency [10], since at low frequency range, the few rooms modes lead to standing waves which dominate the acoustic field. Utley [11] stated that the prediction of the transmission loss depends on the characteristics of the rooms of the test laboratory rather than the intrinsic properties of the structure. Inter-comparisons of the transmission loss between ISO laboratories [12] and ASTM laboratories [13] evidenced that considerable differences up to $8 \mathrm{~dB}$ were found for frequencies below Schroeder frequency due to mounting conditions, frames and apertures.

As reported by many authors [14-16], at very low frequencies, theoretical and experimental approaches of the transmission loss through partition between rooms are highly dependent on the test conditions. In other words, it means that the predictive $T L$ is valid only for the specific case under examination. To overcome this difficulty, numerical methods can be considered as a mean of introducing more representative measurement conditions to study the particularities of each case. In addition to the energetic approach such as Statistical Energy Analysis (SEA) or its improved version the Statistical modal Energy distribution Analysis (SmEdA), many numerical methods are available to solve the problem of acoustic insulating from which we cite the Finite Element Method (FEM) and the Boundary Element Method (BEM). The choice of the adequate one depends on the frequency range of interest and the computational cost. The SEA introduced in $[17,18]$ is based on the statistical energy exchanges of diverse subsystems. Due to the underlying assumptions taken in this method which can be unrealistic in some cases, Maxit et Guyader [19] extended it to SmEdA to take into account the modal 
energy distribution. Despite these improvements, the energetic approaches are reliable only at high and medium frequency range with the view to the significant uncertainties due to the few resonant modes in each of the subdomains [20]. To this end, an hybrid approach was developed by Shorter and Langley [21] that combines the finite element method and statistical energy analysis in a single model. This method consists in modeling the deterministic components with the FEM while the statistical components are described in terms of their vibrational energy with SEA [21]. However, in low frequencies, the subdomains in the building sector have a high modal behavior. For this reason, a more accurate prediction of the sound transmission loss can be reached with the FEM and BEM approaches. Santos et Tadeu [22] considered that the BEM approach could be a good tool to solve unbounded problems due to the satisfaction of the far field conditions. Sgard et al. [23] analysed the transmission loss of a double partition using the FEM for different layers of porous-elastic material mixed with the BEM for the fluid excitation. Only the FEM has been employed by Maluski and Gibbs [24] to investigate the sound insulation of a wall and results pointed out a strong dependence between the $T L$ and the modal behavior of both rooms and of the partition. This dependence has also been studied and demonstrated in [25].

Despite the multiplicity of experimental studies, few approaches confronting experimental measurements to numerical simulations for the study of TL at low frequency for domestic windows can be found in the literatures. Gimeno [26] studied the acoustic insulation of domestic window. Its numerical results diverge in comparison with the experimental measurements. Kwapisz et al. [27] used a 3D model, whose results were satisfactory only from a qualitative point of view compared to the experimental results.

Løvholt et al. [28] studied the effect of windows on the acoustic performance of walls for frequencies below $100 \mathrm{~Hz}$ with also a 3D finite element model. The modeled square windows is made of aluminum and composed of a single casement. The numerical results show that the windows control the acoustic transmission for frequencies from 15 to $30 \mathrm{~Hz}$. The present work concerns the vibro-acoustic response of a full scale domestic wooden windows composed of two casements (Fig. 1) for the frequency range up to $630 \mathrm{~Hz}$. The originality of the proposed research is related to the development of a detailed numerical model of the windows validated by experimental modal analysis and used for the prediction of the TL.

Since windows are mainly mounted in the exterior building facades, the present study is more particularly focused on the transmission of outdoor 
airborne noises which are generally emitted from the traffic corresponding to low-pitched noise [29].

For this end, in the second section, the studied window is presented in details. Then, we will detail the numerical model used to determine the sound transmission loss of the window in witch the source and receiving rooms are removed. In the fourth section, the identification of the window and the calibration of its numerical model are discussed. The laboratory measurements of the sound transmission loss is described in section 5. Finally, we will check the ability of the calibrated numerical model and the proposed configuration to predict the real vibro-acoustic response of the window in the low frequency range.

\section{Window design description}

The schematic of the wooden window under investigation is reported in Fig. 1. It is a French double-leaf window provided by PASQUET company. This designation describes the opening mode of the joinery which opens inside the room with right pulling.

The window is mainly composed of two casements (movable part) which pivot vertically at the edges and rest on the frame (fixed part) which is sealed in the wall. Insertion into the latter is done using a support piece which is a horizontal piece placed on the lower part of the window resting on the masonry. The mechanical connection between the casements and the frame is ensured by six hinges and the seal is ensured by a gasket placed all along the contact surface of these two components.

The closing system is made up of a metal rod and a gear housing which is operated by means of the handle. The dimensions of the window are 1.45 per $1.48 \mathrm{~m} 2$ for a total mass of $76 \mathrm{~kg}$ approximately. The window is made up of about 90 pieces of wood, glass, rubber, metal and other materials.

Each casement of the widow is mainly composed of double glazing incorporated into a wooden frame. The glazing is wedged in the rebate which is the notch made in the thickness of the frame and which is intended to receive the glazing. The positioning of the glazing is carried out using seat and peripheral wedges. Depending on the type of the frame, the arrangement of the wedges varies. The frame of the casement is composed of two leaves and two sashes whose connection, illustrated in Fig. 2, is provided by a screw with a sealing piece made of rubber. The section of the leaves and sashes is presented in Fig. 3. 


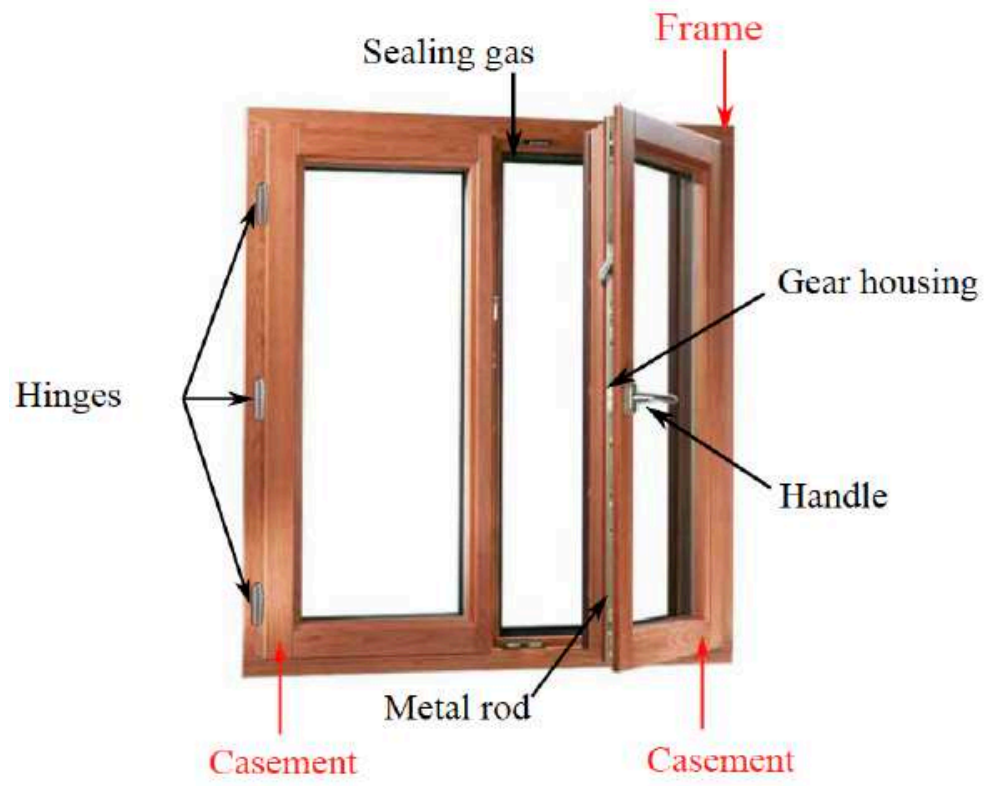

Figure 1: Domestic wooden window.

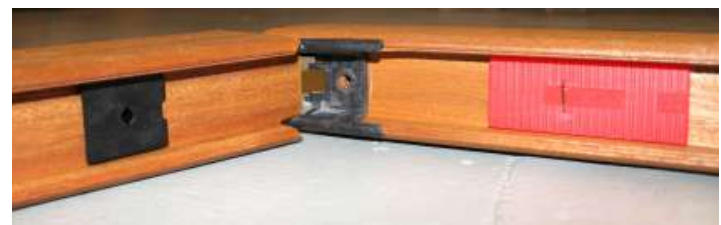

Figure 2: Connection between the leaf and the sash of the casements.

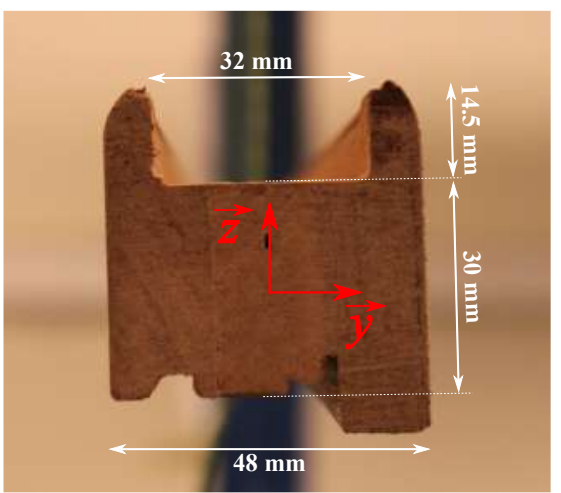

Figure 3: Details of the casements section. 
The double glazing of the window (Fig. 4) is composed by two panels of glass separated by a cavity filled with air or a gaz. The panels are linked together along their perimeters by the edge seal systems. This last consists of numerous components: the spacer bar, the desiccant and the sealant. The stainless hollow steel spacer acts as a rigid support in compression to maintain a fixed distance between the glasses [30, 31]. It is filled with the desiccants, which are used to dry out the cavity of the double glazing glass. Typically, they are molecular sieves or a mix of silica gel with molecular sieves. For the sealant, a dual combination is commonly used. It is composed of a primary sealant placed between the spacer and each glass panels. It is mainly used to eliminate cavity gas loss and vapor penetration [30, 31]. For this purpose, a synthetic rubber, typically polyisobutylene (PIB), is used. The secondary seal, which can be silicone, polyurethane or polysulphide, has several roles for double glazing. In addition to protecting the primary seal and preventing vapor penetrations into the cavity, it represents the mechanical component for the connection of the spacer [30]. In this study, two double glazing systems are considered. The first one, noted $6 / 18 / 4$, is composed of two panels whose thicknesses are $6 \mathrm{~mm}$ and $4 \mathrm{~mm}$, separated by $18 \mathrm{~mm}$ argon cavity. The second system, noted $4 / 20 / 4$, is composed of two panels with the same thickness $(4 \mathrm{~mm})$, separated by $20 \mathrm{~mm}$ argon cavity.

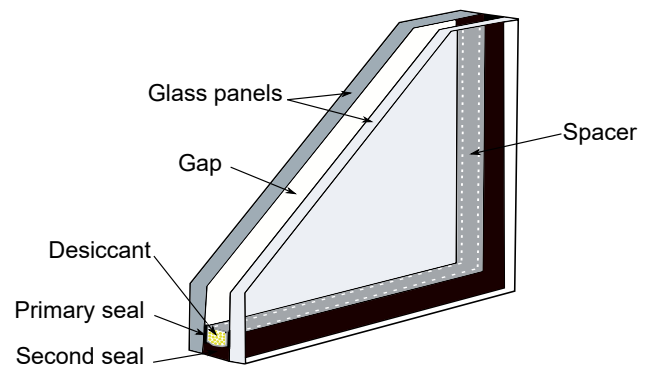

(a)



(b)

Figure 4: IGU: (a) Nomenclature and (b) Edge sealant system.

\section{Numerical prediction of sound transmission loss through a win- dow}

Basically, the sound transmission loss characterizes the acoustic insulation of a structure and it is defined as [14, 32]:

$$
T L=10 \log _{10}\left(\frac{\Pi_{i n c}}{\Pi_{r a d}}\right)
$$


where $\Pi_{\text {inc }}$ and $\Pi_{\text {rad }}$ are the incident and the radiated sound power by the structure, respectively.

In experimental measurements, the acoustic tests are carried out in a laboratory composed of two reverberant rooms separated by a wall. This last contains an opening in which the test element is mounted. The incident and transmitted sound power are determined by measuring the average sound pressure levels $L_{e}$ and $L_{r}$ in the emitting and the receiving room, respectively. So that, for a test specimen whose area is $S$, the $T L$ is determined as:

$$
T L=L_{e}-L_{r}+10 \log _{10} \frac{S}{A}
$$

where $A$ is the equivalent sound absorption area in the receiving room.

To reproduce numerically this acoustic experimental tests, several configurations have been studied and analyzed by the authors in ref. [33]. The configuration where the source and receiving rooms are removed and a perfect field is considered in the both side of the structure to test (Fig. 5), turned out to be the best compromise between precision of results and numerical cost. In fact, this configuration ensures a perfect diffuseness of the acoustic field even at the very low frequency range and so avoids the modal behavior of the two rooms. Additionally, due to its computational efficiency, results of the $T L$ of different double-glazing issued from this model have been compared to experimental results. For the whole frequency range even for those below $100 \mathrm{~Hz}$, the comparison showed a good agreement between numerical and experimental approaches. This configuration, when the baffled structure is excited by a diffuse field on the emitting side and radiates in a free field in the receiving one, will be used throughout this work. The structure to be tested (double glazing or window) is modeled by finite elements method using a $(\mathbf{u}, p)$ formulation. In this case, the radiated sound power is calculated with the Rayleigh integral method [34].

\subsection{Finite elements formulation of the problem}

A fully-coupled fluid-structure finite elements model was used in this work to represent the vibratory behavior of the structure containing a cavity filled with a gas (double or triple glazing). In this model, the structure is described by its displacement field $\mathbf{u}$ and the cavity by its pressure field $p$. The discretization of the variational formulation associated to the problem 


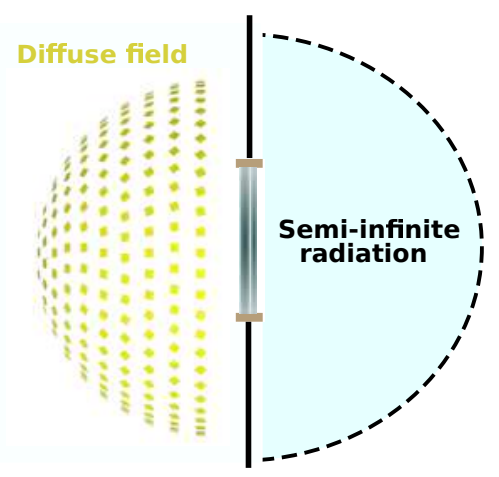

Figure 5: DSF-structure-free field configuration.

$[35,36]$ leads to this matrix system (see Ref. [37] for details):

$$
\left(\left[\begin{array}{cc}
\mathbf{K}_{u} & -\mathbf{C} \\
\mathbf{0} & \mathbf{K}_{p}
\end{array}\right]-\omega^{2}\left[\begin{array}{cc}
\mathbf{M}_{u} & \mathbf{0} \\
\mathbf{C}^{T} & \mathbf{M}_{p}
\end{array}\right]\right)\left[\begin{array}{l}
\mathbf{U} \\
\mathbf{P}
\end{array}\right]=\left[\begin{array}{l}
\mathbf{F} \\
\mathbf{Q}
\end{array}\right]
$$

where $\mathbf{K}_{u}$ and $\mathbf{M}_{u}$ are the structural stiffness and mass matrices, $\mathbf{K}_{p}$ and $\mathbf{M}_{p}$ are the associated acoustic matrices, $\mathbf{C}$ is the fluid-structure coupling matrix, $\mathbf{F}$ is the nodal force excitation and $\mathbf{Q}$ is the nodal acoustic excitation. The structural and acoustic domains are subdivided into finite elements whose sizes are controlled by the wavelength $\lambda(\mathrm{m})$ which depends on the frequency range of interest. For the fluid domain, we consider the acoustic wavelength defined as $\lambda_{a}=c_{0} / f$ where $c_{0}$ is the sound speed. For the structure, the bending wavelength is $\lambda_{f}=\sqrt{(2 \pi / f)}(D / M)^{1 / 4}$ where $D\left(\mathrm{~Pa} . \mathrm{m}^{3}\right)$ is the bending stiffness and $M(\mathrm{~kg} / \mathrm{m})$ is the surface mass density. At the interface between the structure and acoustic domains, coupling interfaces are enforced and the resolution is performed with direct approach.

\subsection{Diffuse sound field formulation}

At low frequencies, to treat the problem by respecting the condition of incident diffuse sound field, it is necessary to model a room whose dimensions are much larger than the wavelength. This necessity increases the computational costs. To overcome this problem, a diffuse field is applied to the structure to be tested which make it possible to avoid the modelling of the emitting chamber.

To create a diffuse field, the plane wave approach is used [38]. It consists in superimposing an infinity of random plane waves in phase, arriving 
uniformly from all directions and whose propagation vector is oriented towards the structure $[34,39]$. This excitation makes it possible to take into account all the possible incidences without favoring any direction. From this definition, the pressure field generated by a diffuse field on the structure is obtained by the integration of the pressure of each plane wave whose angle of incidence is defined on a half-hemisphere on the incidence side [23], as shown in Fig. 6. Therefore, the pressure at an observation point marked by $\mathbf{r}$ is defined by:

$$
p(\mathbf{r}, t)=A_{o p} \int_{0}^{2 \pi} \int_{0}^{\pi / 2} e^{-j(\mathbf{k} . \mathbf{r})} e^{j(\omega t+\phi)} \sin \varphi d \theta d \varphi,
$$

where $A_{o p}$ is the amplitude of a plane wave identified in space by longitude angle $\theta$ and colatitude angle $\varphi$, and $\phi(\theta, \varphi)$ represents the random phase of the wave.

The incident (or radiated) sound power through a structure surface $S$ is given by:

$$
\Pi=\frac{1}{2} \operatorname{Re}\left(\iint p v_{n}^{*} d S\right),
$$

where $v_{n}$ is the normal velocity at any point of the structure, $R e$ is the real part of a complex number and $*$ indicates the conjugated complex.

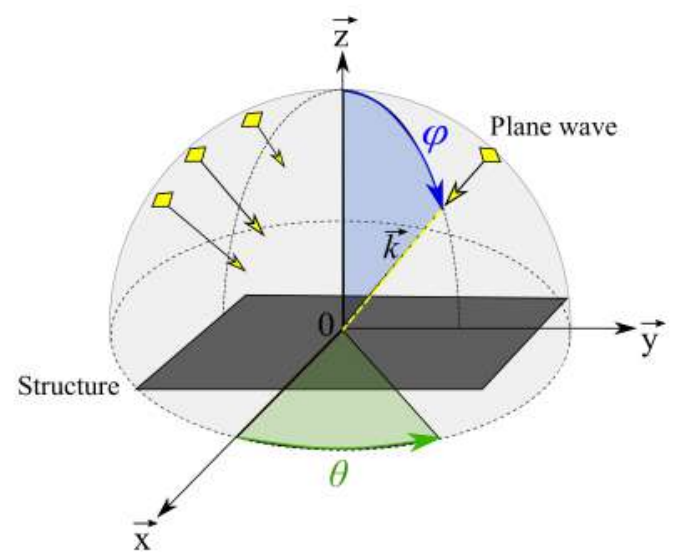

Figure 6: Excitation of a structure by an acoustic diffuse field.

According to the normal direction $z$, the normal velocity vector can be obtained from the Euler equation and the pressure and it is written in the form:

$$
v_{n}(\mathbf{r}, t, \varphi)=\frac{A_{o p}}{\rho_{0} c_{0}} e^{j(\omega t-\mathbf{k} . \mathbf{r}+\phi)} \cos \varphi
$$


The substitution of the sound pressure field (Eq. (4)) and the normal velocity (Eq. (6)) in Eq. (5), the incident sound power by the diffuse field $\Pi_{i n c}^{d}$ becomes

$$
\Pi_{i n c}^{d}=\frac{\left|A_{o p}\right|^{2}}{2 \rho_{0} c_{0}} \int_{0}^{2 \pi} d \theta \int_{0}^{\pi / 2} \cos \varphi \sin \varphi d \varphi
$$

In the case where we assume that there are $N$ uncorrelated plane waves with a constant unit amplitude $A_{o p}$, the pressure field can be determined from:

$$
p(\mathbf{r}, t)=\frac{1}{\sqrt{N}} \sum_{n=1}^{N} e^{-j(\mathbf{k} . \mathbf{r})} e^{j(\omega t+\phi)},
$$

\subsection{Rayleigh integral formulation}

When the excited structure radiate in an anechoic receiving room and the modal behavior of this room is negligible, the acoustic sound power radiated by the structure can be calculated using the Rayleigh integral method without $3 \mathrm{D}$ modelling of the receiving room. We recall that the radiated sound power through a structure area $S$ is given by Eq. (5). The sound pressure $p$ of a flat plate mounted in an infinite rigid baffle and radiating in a semi-infinite fluid can be determined with the Rayleigh Integral [40]:

$$
p(\omega, M)=\rho_{0} \frac{i \omega}{2 \pi} \int_{S_{2}} v_{n}(\omega, G) \frac{e^{-i k r}}{r} \mathrm{~d} S,
$$

where $G$ is a point on the plate surface, $\rho_{0}$ is the mass density of the external acoustic domain, $k$ is the wave number expressed as $\omega / c_{0}, c_{0}$ is the acoustic speed of sound, $M$ is a point inside the external acoustic domain and $v_{n}(\omega, G)$ is the normal velocity at point $G$ expressed as $v_{n}(\omega, G)=\mathbf{v}(G, \omega) \cdot \mathbf{n}_{S}$ and where $\mathbf{n}_{S}$ is the unit vector normal external to the structure. Thanks to the previous finite element formulation, the distribution of the normal velocity on the structure can be determined.

The baffled panel is divided into $R$ rectangular equal elements whose area is noted $S_{e}$. The transverse vibration of each element is specified in terms of the normal velocity at its center position. Assuming that the structural and the acoustic wavelengths are larger than the dimensions of the element, the total radiated sound power (Eq. (5)) can be expressed as the summation of the powers radiated by each element, so that:

$$
\Pi_{t}=\frac{S_{e}}{2} \operatorname{Re}\left(\mathbf{v}_{n}^{H} \mathbf{p}\right),
$$

where the superscript $H$ denotes the Hermitian transpose, $\mathbf{v}_{n}$ and $\mathbf{p}$ are the vectors of complex amplitudes of the normal volume velocity and acoustic 
pressure in all elements. The pressure on each element is generated by the vibrations of all elements of the panel, so that, its vector can be expressed by the impedance matrix:

$$
\mathbf{p}=\mathbf{Z v}_{n}
$$

where $\mathbf{Z}$ is the matrix incorporating the point and transfer acoustic impedance

terms over the grid of elements: $Z_{i j}=\left(i \omega \rho_{0} S_{e} / 2 \pi r_{i j}\right) e^{-i k r_{i j}}\left(r_{i j}\right.$ is the distance between the centers of the $i^{t h}$ and $j^{t h}$ elements). Due to the reciprocity, $\mathbf{Z}$ is a symmetric matrix. The substitution of Eq. (11) into the expression for the total radiated sound power Eq. (10) allows to have the following expression:

$$
\Pi_{t}=\frac{S_{e}}{2} \operatorname{Re}\left(\mathbf{v}_{n}^{H} \mathbf{Z} \mathbf{v}_{n}\right)=\frac{S_{e}}{4} \operatorname{Re}\left(\mathbf{v}_{n}^{H}\left[\mathbf{Z}+\mathbf{Z}^{H}\right] \mathbf{v}_{n}\right)=\mathbf{v}_{n}^{H} \mathbf{R} \mathbf{v}_{n},
$$

The matrix $\mathbf{R}$ is defined as the "radiation resistance matrix" for the elementary radiators which, for the baffled panel, is given by

$$
\mathbf{R}=\frac{\omega^{2} \rho_{0} S_{e}^{2}}{4 \pi c_{0}}\left[\begin{array}{cccc}
1 & \frac{\sin \left(k r_{12}\right)}{k r_{12}} & \ldots & \frac{\sin \left(k r_{1 R}\right)}{k r_{1 R}} \\
\frac{\sin \left(k r_{21}\right)}{k r_{21}} & 1 & \ldots & \frac{\sin \left(k r_{2 R}\right)}{k r_{2 R}} \\
\vdots & \vdots & \ddots & \vdots \\
\frac{\sin \left(k r_{R 1}\right)}{k r_{R 1}} & \frac{\sin \left(k r_{R 2}\right)}{k r_{R 2}} & \ldots & 1
\end{array}\right]
$$

This method can be applied to any plane surface in an infinite baffle, independently of the boundary conditions. It only requires the knowledge of the surface geometry, the characteristics of the fluid and the velocity field distribution. In this work, a finite element approach is used to evaluate this velocity field by using a sufficient number of discrete radiating elements according to the smallest wavelength to be observed.

\section{Calibration of the window's numerical model}

\subsection{Experimental Modal Analysis set-up}

The characterization of the window's modal parameters such as the natural frequencies and the modal shapes is done with the Experimental Modal Analysis (EMA) whose general set-up is presented by Fig. 7. To this end, in this study, the suspended window (see Fig. 8), which is $1.45 \mathrm{~m}$ wide by $1.48 \mathrm{~m}$ high, is meshed into 600 points. Measurements of the acceleration are done at all the mesh points with an average of three impacts using a laser vibrometer. For the application of the force, a shaker is used. The EMA is performed up to $800 \mathrm{~Hz}$ with a frequency resolution of $0.5 \mathrm{~Hz}$. 


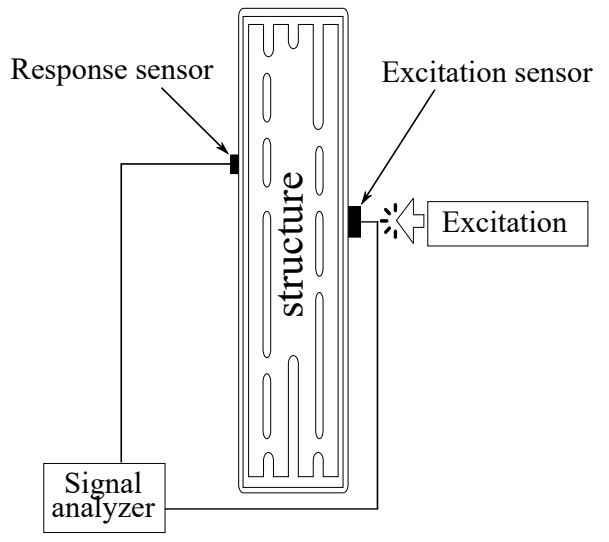

Figure 7: The general set-up of Experimental Modal Analysis.

For performing the EMA, a home-made Matlab toolbox has been developed and includes several approaches like LSCF [41] and its polyreference version [42]. This toolbox consists of several Matlab routines, allowing to establish the complete modal analysis from experimental data step by step.

To ensure the reliability of the experimental measurements, verification tests were carried out. These tests concern the verification of the reciprocity and the verification of the independence to the excitation level:

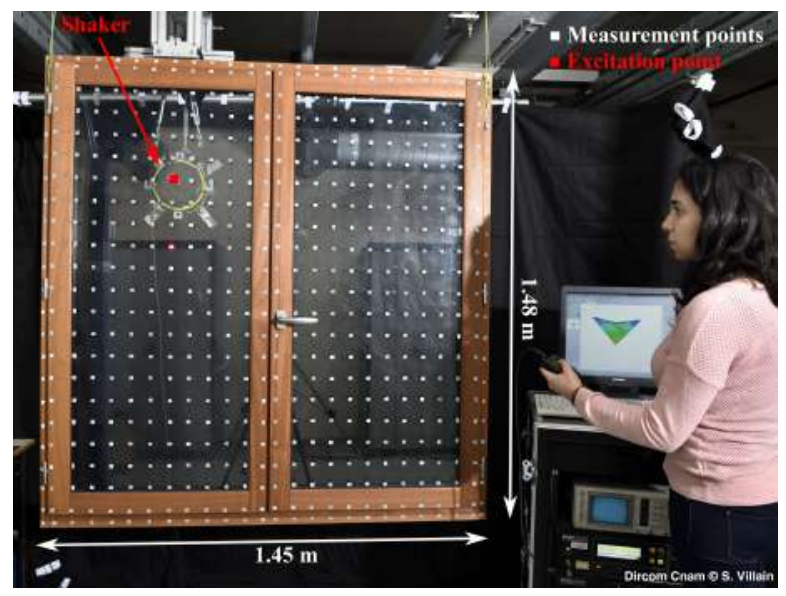

Figure 8: Suspended window for the EMA.

\section{- Reciprocity}

The principle of reciprocity must be verified if the structure is supposed to 
be linear. It means that the FRF measurements of two points must be the same regardless of which of them is the input or the output. For this, three cases are studied; the first one where the excitation and the measurement points, respectively, V1 and V2, are in the opposite glasses. For the second case, the excitation point is in the the wooden frame and the measurement point is in a panel glass $(\mathrm{C}-\mathrm{V})$. Finally for the third case, the excitation point $\mathrm{P} 1$ and the measurement point $\mathrm{P} 2$ are on the same panel glass. The comparisons of the FRF (Fig. 9) show that the system is linear since the curves are superposed following the permutation between the excitation and measurement points.

\section{- Independence to the excitation level}

The linearity of the system is also verified by the independence of the transfer function of the structure following a variation in the excitation energy level.

Several acceleration measurements were taken for different intensities of force (Fig. 10a). The results of Fig. 10b show that the transfer function between input and output is unchanged for the frequency range of interest. Therefore, a linear numerical model can be used for the wooden window.

\subsection{EMA of the wooden window}

The shaker has been suspended parallel to the structure with an adjustable support to optimize its position so that the excitation is always normal to the structure. The rod used allows the shaker to be connected to an impedance head. The latter allows a co-localized measurement of the force and acceleration at the excitation point.

Once the test is completed, ensure that the scanning of the structure by the laser vibrometer is performed and that the response of all nodes of the mesh is recorded. In our case, and after several adjustments, a measurement of all points is obtained (see Fig. 11).

For this test, the shaker excites the window with a white noise whose energy is concentrated in the frequency band of interest.

Once the experimental modal analyses have been performed, we proceed to the extraction of the modal parameters that will be used to adjust the equivalent numerical models of the window and its subsystems.

\subsection{Numerical calibrated model}

Geometry : We started by proposing the simplest possible designs. The first proposed design consists of two identical sashes fixed on their contours without adding any other components. The numerical results were 


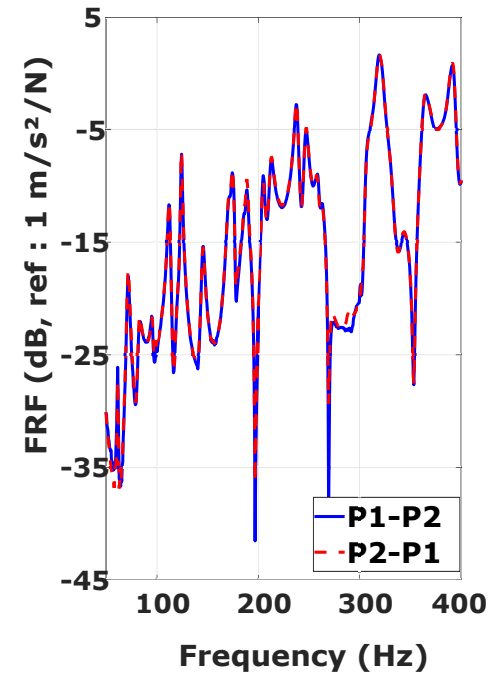

(a) opposed glass

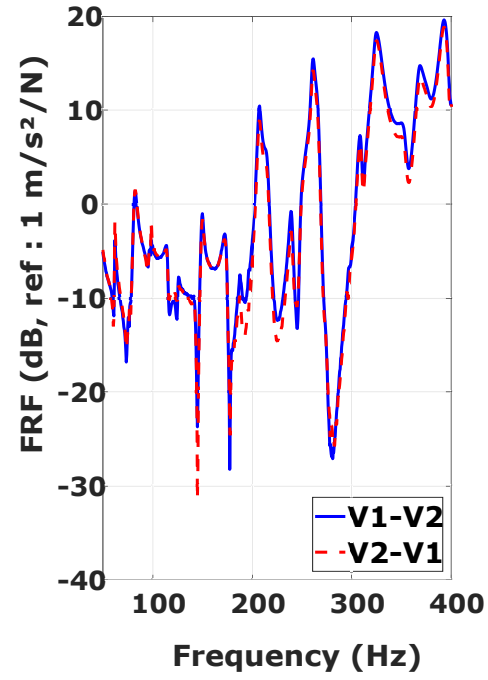

(b) sash-glass

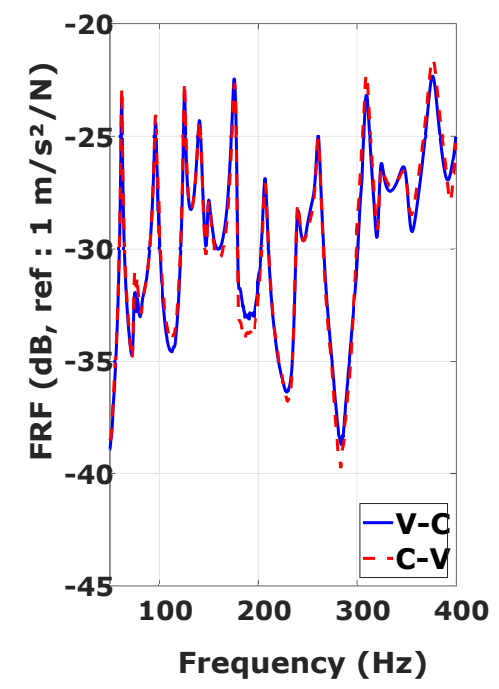

(c) Excitation and measurements done in the same glass

Figure 9: Verification of the reciprocity. 


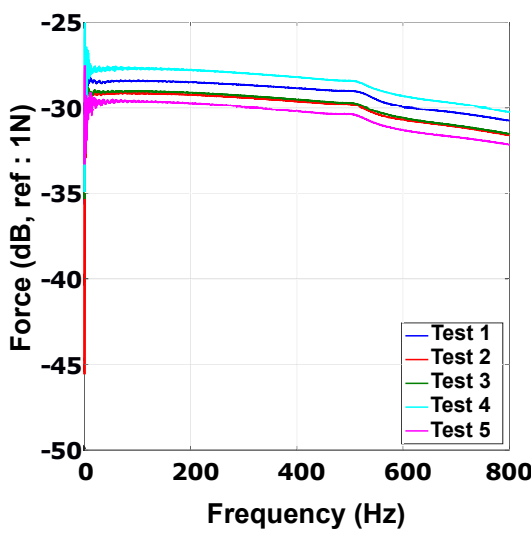

(a) Force

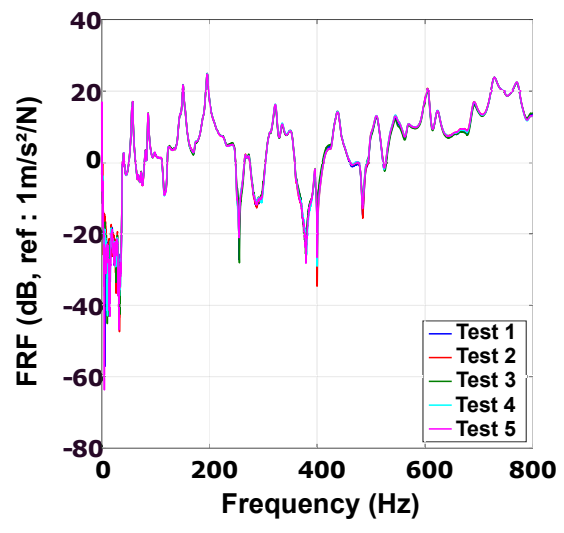

(b) FRF

Figure 10: Verification of the independence to the excitation level.

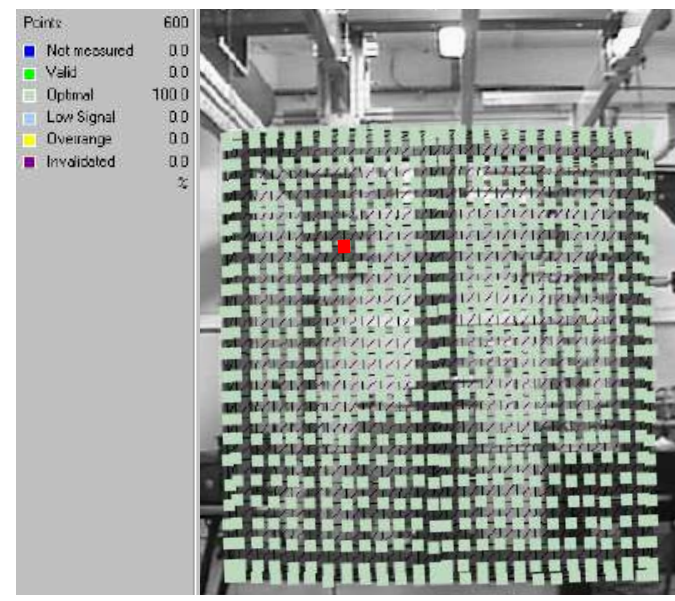

Figure 11: Verification of the scanning's quality of the window by the laser vibrometer. 
not consistent with those of the experiment. In fact, it has been shown by Bedon et al [43] that secondary components of the window and the assemblies assured by joint have an influence on the EMA results. So that, in the second proposal, a frame was added to support the first model, again giving a very rigid model. After improvements, the final model, presented in Fig. 12 is composed of two casements spaced $5 \mathrm{~mm}$ apart and linked together by a wooden plate at the closure. They are placed on the frame by means of a $2 \mathrm{~mm}$ thick rectangular joint that extends over the entire contact surface between the two casements and the frame.

Mesh : The mesh of the equivalent window model is shown in the second line of the Fig. 12. A compatible mesh between the sashes, bar, joint and frame has been used with linear hexahedral elements. Since it is recommended to use 6 linear elements per acoustic wavelength, and 10 elements for the bending wavelength [44], the final model contains around 141000 degrees of freedom.
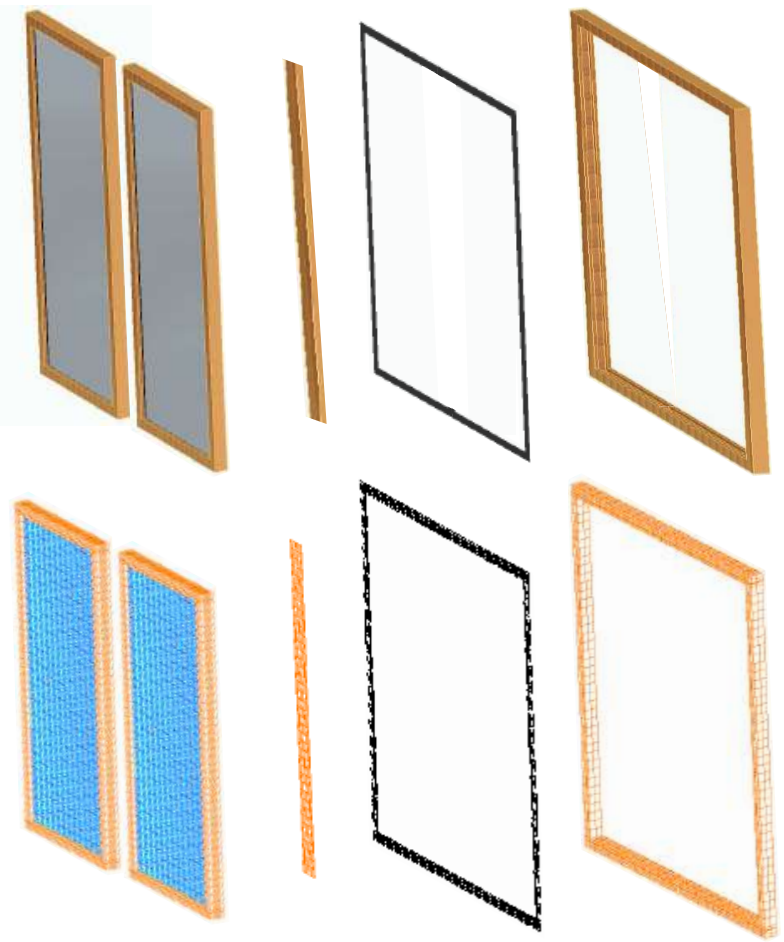

Casements

Wooden

Joint

Frame

Figure 12: Differents components of the window (CAO et FEM model). 
Properties of Materials : The material properties used for the insulating double glazing, the joint and the wedges are presented in Tab. 1. For the double glazing, these properties are calibrated from the EMA and details are presented in a previous paper [33].

Table 1: Mechanical properties of the materials of the insulating double glazing, the joint and the wedge.

\begin{tabular}{ccccc}
\hline \hline Components & Panels & Equivalent spacer & Joint & Wedge \\
\hline Materials & Glass & Equivalent material & Rubber & PVC \\
$E(\mathrm{GPa})$ & 60 & 0.1 & 0.1 & 0.5 \\
$\rho\left(\mathrm{kg} / \mathrm{m}^{3}\right)$ & 2450 & 1523 & 1200 & 571 \\
$\nu$ & 0.23 & 0.49 & 0.49 & 0.3 \\
\hline
\end{tabular}

At this stage, only the wooden's properties are unknown. The existence of different types of wood brings great diversity in terms of design. Therefore, many products are derived from wood in order to reduce intrinsic variability and make it more homogeneous. These derived products are made from strips of wood glued and joined together. The reconstitution by gluing makes the assembled element more reliable and also less anisotropic. As a result, the wood is considered as transverse isotropic and is described by five independent components [45]. For this study, the density $\rho_{w}$ is calibrated from the volume and the mass of the frame. A value of 0.3 is fixed for the Poisson's ratios and the shear modulus $G$ is chosen as $650 \mathrm{MPa}$ from the ISO 14080 standard [46]. For the Young's moduli, the value $E_{L}$ along the longitudinal axis is obtained from the beam theory. Two bending tests and a compression one along the three directions $(\vec{x}, \vec{y}$ and $\vec{z})$ are carried out (Fig. 13). As a result, three values are obtained, thus giving an average of $12.5 \mathrm{GPa}$ for $E_{L}$. For the Young's modulus $E_{T}$ along the transversal axis, it is determined from the numerical calibration of the frame's model using the EMA and a value of $9 \mathrm{GPa}$ is obtained.

\subsection{Results of the model calibration}

The first ten experimental and numerical eigenfrequencies as well as the associated deviations are summarized in the Tab. 2. The relative error of the first frequency is $0.3 \%$. For the rest of the modes the deviation does not exceed $10 \%$ with a maximum value of $9.2 \%$ observed in mode 8 . These results do not allow to conclude about the rigidity of the proposed model. In fact, it is observed that for certain modes (modes 1, 3, 5, 6 and 7) the 


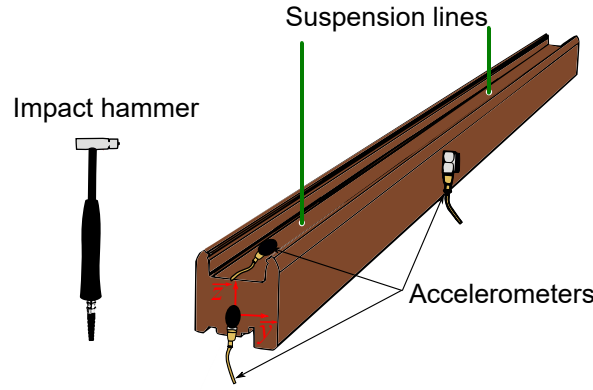

Figure 13: Suspended beam for FRF measurement to determinate the Young's moduli of the wood.

numerical eigenfrequencies are greater than the experimental ones, while for other modes the phenomenon is reversed.

Table 2: Comparison of the first ten experimental and numerical eigenfrequencies of the window.

\begin{tabular}{ccccccccccc}
\hline \hline Mode & $\mathbf{1}$ & $\mathbf{2}$ & $\mathbf{3}$ & $\mathbf{4}$ & $\mathbf{5}$ & $\mathbf{6}$ & $\mathbf{7}$ & $\mathbf{8}$ & $\mathbf{9}$ & $\mathbf{1 0}$ \\
\hline Experimental (Hz) & 18.04 & 29.5 & 38.3 & 40 & 40.9 & 56 & 57.2 & 67.2 & 68.2 & 72.6 \\
Numerical (Hz) & 18.1 & 27.2 & 39.2 & 39.8 & 42.9 & 59.7 & 61.7 & 61 & 63.9 & 70 \\
Error (\%) & -0.3 & 7.7 & -2.4 & 0.5 & -5 & -6.7 & -7.9 & 9.2 & 6.4 & 3.6 \\
\hline
\end{tabular}

The corresponding modal deformations are presented in the Fig. 14. A very good agreement can be observed between the experimental and numerical results for all the modes. However, it can be seen that mode 3 and mode 10 only interest the half of the structure. In fact, the two casements of the window are not identical and there is one larger than the other (asymmetrical system) which gives a few modes which decouple the two parts of the structure and the modal deformation concerns only one casement.

The MAC (Modal Assurance Criterion) is also used out to evaluate the coherence of experimental and numerical modal vectors [47]. The MAC calculated from the comparison of the ten first modal shapes is presented in Fig. 15. The MAC confirms the similarities of the modes with diagonal terms close to 0.9, except for the eighth mode where the value is 0.5. For such a complex structure, the results are considered satisfactory.

Regarding the comparison of the eigenfrequencies and the modal shapes, the calibrated numerical model of the window is satisfying, and therefore, it is used for the prediction of the sound transmission loss. 


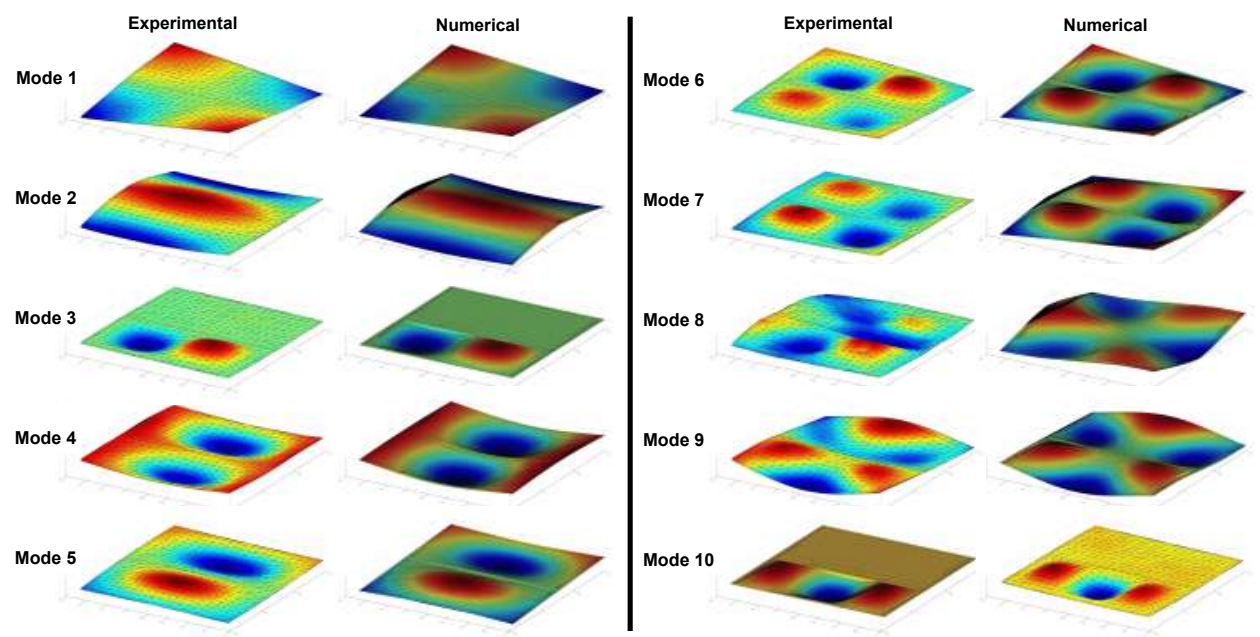

Figure 14: Comparison of the first ten experimental and numerical mode shapes of the window.

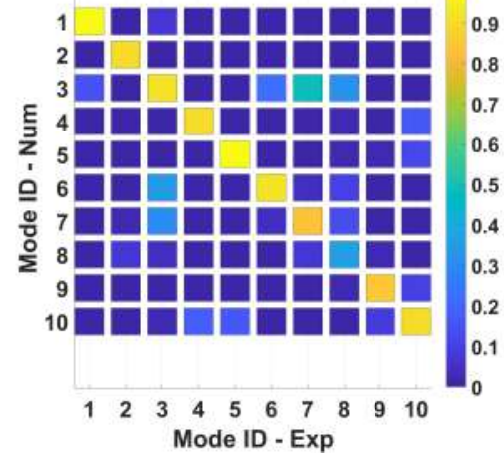

Figure 15: MAC of experimental and numerical mode shapes of the window. 


\section{Measurement of window's transmission loss}

Acoustic tests for the evaluation of the sound transmission loss of the windows considered in this chapter are carried out in the CERIBOIS laboratory. The experimental installation is composed of two parallelepiped reverberation chambers (see Fig. 16). The transmitting chamber, presented in the Fig. 16a, is of dimension $4,5 \times 3,25 \times 5 \mathrm{~m}^{3}$ and the receiving chamber, presented in the figure $16 \mathrm{~b}$, is of dimension $4 \times 3,25 \times 5 \mathrm{~m}^{3}$. In order to avoid the solid transmissions that can take place between the two chambers, they are mounted on elastic supports, an example of which is shown in the Fig. 17. On the other hand and for the same purpose, the walls of the rooms are $45 \mathrm{~cm}$ thick. They are composed of two concrete layers of $23 \mathrm{~cm}$ and $20 \mathrm{~cm}$, separated by a $2 \mathrm{~cm}$ layer of compressed foam. The doors of the two rooms have high sound insulation. To obtain a diffuse sound field in both chambers, diffusers are used to increase the reflection of the waves. These elements can be fixed to the walls or suspended from the ceiling, as shown in the Fig. 16.

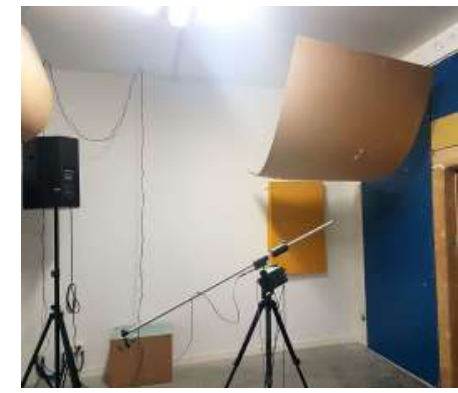

(a) Emitting room

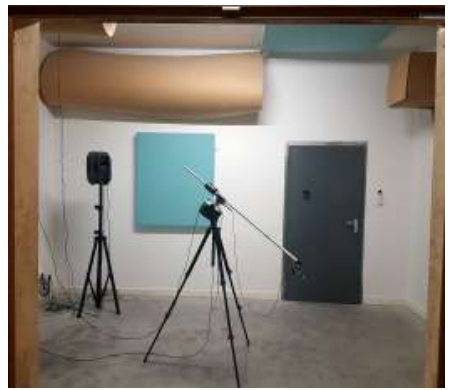

(b) Receiving room

Figure 16: The two chambers of CERIBOIS laboratory.

Fig. 18 shows the placement of the window to be tested in the wall opening between the two chambers according to ISO 140-1 [5]. This standard requires the filling of the gap between the specimen and the opening with an absorbent material. In addition, a sealing material (usually silicone) is spread on both sides around the entire periphery of the window.

\section{Prediction ability of the calibrated numerical model}

This section aims at assessing the prediction ability of the calibrated numerical model described in section 4 . To this end, the $T L$ computed from the 

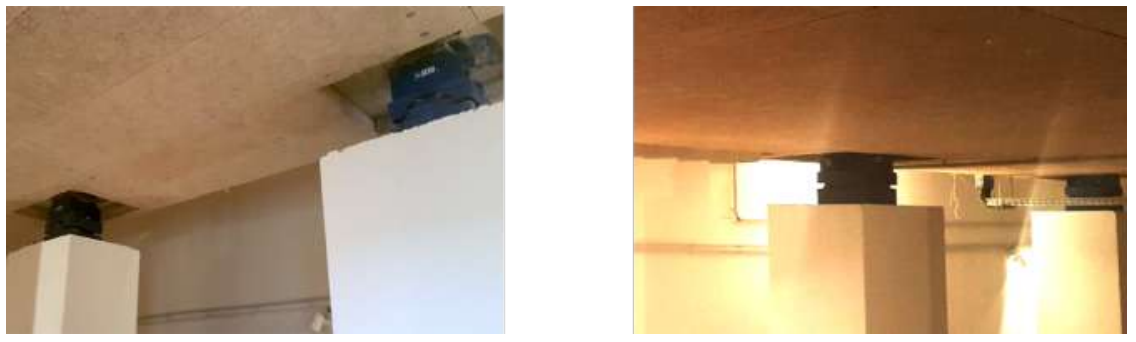

Figure 17: Example of the elastic supports of the chambers of the acoustic laboratory.

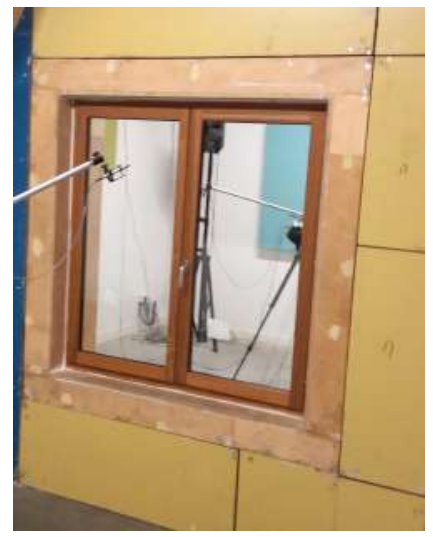

(a) Emission chamber side

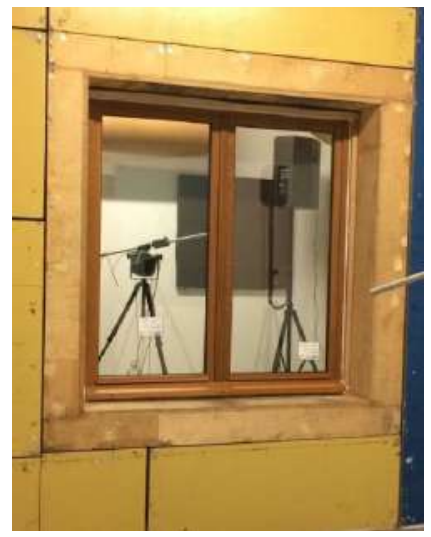

(b) Receiving chamber side

Figure 18: Mounting of the window in the wall for the acoustic tests in the CERIBOIS laboratory. 
proposed model is compared with that measure in the CERIBOIS laboratory for two windows configurations at low frequencies. These configurations differ by the structure of the double glazing. Indeed, the first configuration considers a symmetric double glazing $(4 / 20 / 4)$, while the second one considers an asymmetric structure $(6 / 18 / 4)$.



Figure 19: Window components exposed to acoustic excitation and those radiating in a free field.

\subsection{Symmetric configuration}

As shown in Fig. 20, the comparison in third-octave bands of the $T L$ computed from calibrated numerical model with that measured in the CERIBOIS laboratory is quite satisfactory. Indeed, the prediction error is less than 2,5 dB on average, except for the two first third-octave bands, centered around $50 \mathrm{~Hz}$ and $80 \mathrm{~Hz}$, for which the prediction error of 4,5 dB is observed. Consequently, the proposed calibrated model is judged sufficiently reliable to predict the acoustic performances of the considered window in the low frequency range.

\subsection{Asymmetric configuration}

In the case of an asymmetric configuration, the prediction ability of the proposed calibrated model is less good than in the previous case, since the prediction error doesn't exceed $3,5 \mathrm{~dB}$, except in the third band, centred around $160 \mathrm{~Hz}$, for which the difference is $4.3 \mathrm{~dB}$. In this frequency band lies the so-called "mass-air-mass" frequency, which is predicted by our model but not measured experimentally. Furthermore, it should be noted that the differences observed for the present configuration are more pronounced than in the previous case. This can be potentially explained by a slight change of the geometry of the casement since the experimental identification was carried out on the symmetric window $(4 / 20 / 4)$. However, the overall 


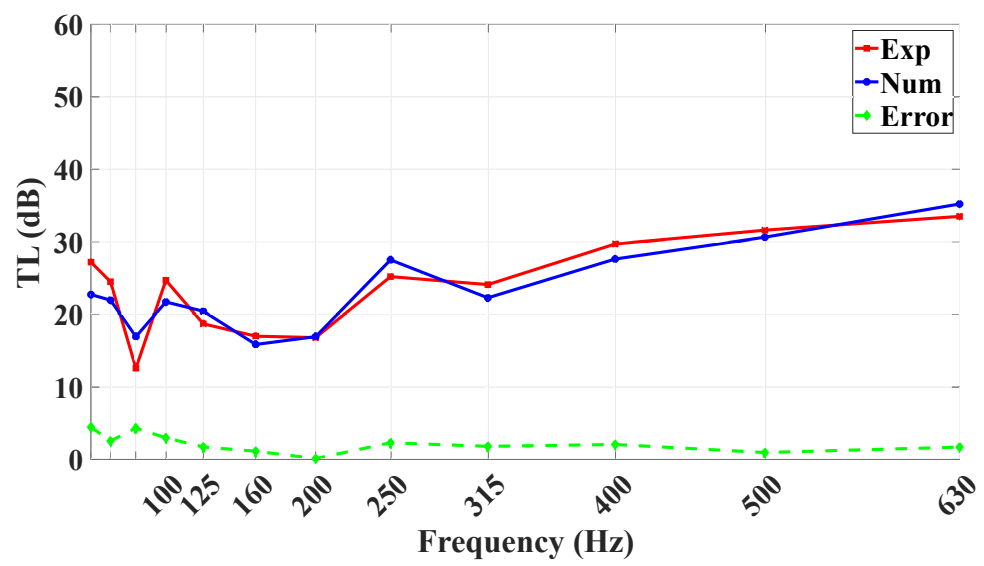

Figure 20: Comparison of the $T L$ of the window with a symmetric double glazing (4/20/4) (-) measured in the CERIBOIS laboratory and (-) computed from the calibrated numerical model

comparison of both results remains satisfying regarding the complexity of the window, which is an assembly of about 90 parts.

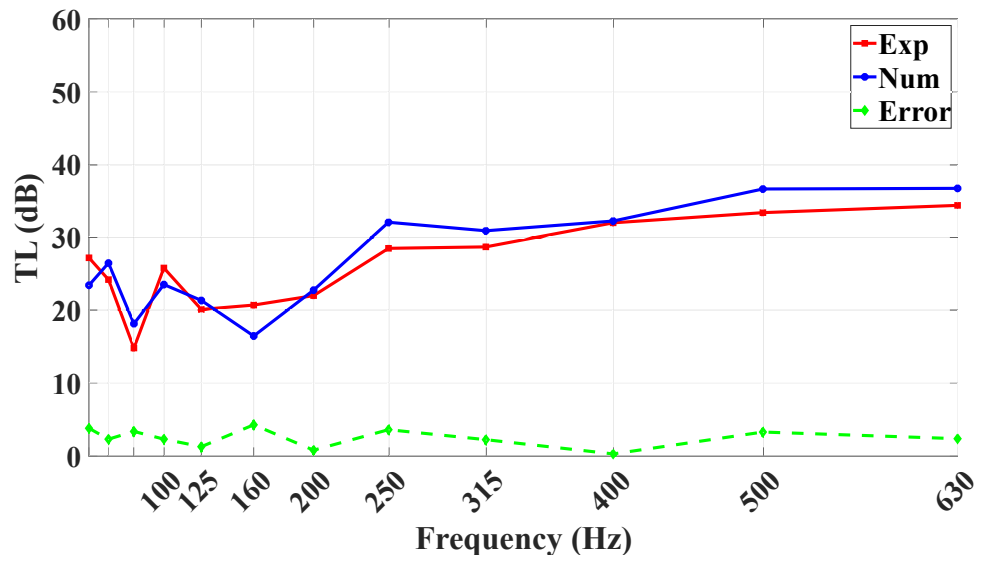

Figure 21: Comparison of the $T L$ of the window with an asymmetric double glazing (6/18/4) (-) measured in the CERIBOIS laboratory and (-) computed from the calibrated numerical mode. 


\section{Conclusions}

The sound Transmission Loss $(T L)$ of a full window at low frequencies has been studied using the Finite Element Method. In order to study the intrinsic response of the structure, a configuration where the two reverberant rooms are removed and a perfect field is considered in the both side is used.

The numerical model of the window has been calibrated with an Experimental Modal Analysis. This step is essential to built the numerical model of the structure due to geometrical and mechanical complexities of the different components. In addition, it has reported by Bedon $[48,49]$ that the possible degradation issues in the joints and window components can modify the measured frequencies. However, it should be mentioned that this aspect has not been studied in this work, as the aim is to have a representative model of a sane system, such as those used in the certification of a product. The modal damping obtained from the EMA, not discussed here, will be used in future work using the modal approach.

The perfect configuration that combines free-fields on both sides of the structure ensures diffuseness of the acoustic field even for the very low frequencies and avoids the modal behavior of the two rooms. Consequently, the problem of the lack of reproducibility will not be faced since this configuration evaluates only the intrinsic performances of the tested element. Results issued from this configuration applied to the calibrated FEM model of the window have been compared to experimental results of models with different glass composition $(4 / 20 / 4$ and 6/18/4). Results showed a good agreement between numerical and experimental results for the whole frequency range even for those below $100 \mathrm{~Hz}$.

Further investigations of this work concerns the introduction of reduced order models in order to reduce the numerical calculation cost and the application of the proposed methodology to wood windows door.

\section{Acknowledgements}

The authors would like to express their thanks to CODIFAB (Comité professionnel de développement des industries françaises de l'ameublement et du bois) for its financial support. 


\section{References}

[1] ISO 12354 : Acoustique du bâtiment - Calcul de la performance acoustique des bâtiments à partir de la performance des éléments : Partie 3: Isolement aux bruits aériens venus de l'extérieur, 2017.

[2] C. Díaz and A. Pedrero. An experimental study on the effect of rolling shutters and shutter boxes on the airborne sound insulation of windows. Applied Acoustics, 70(2):369-377, 2009.

[3] S. Pietrzko and Q. Mao. Vibration identification and sound insulation of triple glazing. Noise Control Engineering Journal, 61(3):345-354, 2013.

[4] B. Naticchia and A. Carbonari. Feasibility analysis of an active technology to improve acoustic comfort in buildings. Building and Environment, 42(7):2785-2796, 2007.

[5] ISO 10140 : Acoustique - Mesurage en laboratoire de l'isolation acoustique des éléments de construction : Partie 1: Règles d'application pour produits particuliers, 2016.

[6] ISO 10140 : Acoustique - Mesurage en laboratoire de l'isolation acoustique des éléments de construction : Partie 2: Mesurage de l'isolation au bruit aérien, 2013.

[7] ISO 10140 : Acoustique - Mesurage en laboratoire de l'isolation acoustique des éléments de construction : Partie 4 : Exigences et modes opératoires de mesure, 2013.

[8] ISO 10140 : Acoustique - Mesurage en laboratoire de l'isolation acoustique des éléments de construction : Partie 5: Exigences relatives aux installations et appareillage d'essai, 2013.

[9] H. Nélisse and J.Nicolas. Characterization of a diffuse field in a reverberant room. Acoustical Society of America, 101(6):3517-3524, 1997.

[10] M. R. Schroeder. The "Schroeder frequency" revisited. Acoustical Society of America, 99(5):3240-3241, 1996.

[11] W. A. Utley. Single leaf transmission loss at low frequencies. Journal of Sound and Vibration, 8(2):256-261, 1968.

[12] T. Kihlman and A. C. Nilsson. The effects of some laboratory designs and mounting conditions on reduction index measurements. Journal of Sound and Vibration, 3(24):349-364, 1972. 
[13] R. E. Jones. Intercomparisons of laboratory determinations of airborne sound transmission loss. Acoustical Society of America, 66(1):148-164, 1979 .

[14] F. Fahy. Sound and structural vibration: radiation, transmission, and response. Academic Press, London ; Orlando, 1987.

[15] D. B. Pedersen, J. Roland, G. Raabe, and W. Maysenhölder. Measurement of the low-frequency sound insulation of building components. Acta Acustica united with Acustica, 86(3):495-505, 2000.

[16] A. Prato and A. Schiavi. Sound Insulation of Building Elements at Low Frequency: A Modal Approach. Energy Proced., 78:128-133, 2015.

[17] E. E. Unger. Statistical Energy Analysis of vibrating systems. Journal of Engineering for Industry, 89:626-632, 1967.

[18] R. H. Lyon. Statistical Energy Analysis of Dynamical Systems. Theory and Application. MIT Press, 1975.

[19] L. Maxit and J.-L. Guyader. Statistical modal energy distribution analysis(smeda). In Proceedings of Sixth International Congress on Sound and vibration, Copenhagen, Denmark, 1999.

[20] A. Tadeu and J. M. P. António. Acoustic insulation of single panel walls provided by analytical expressions versus the mass law. Journal of sound and vibration, 257(3):457-475, 2002.

[21] P. J. Shorter and R. S. Langley. Vibro-acoustic analysis of complex systems. Journal of Sound and Vibration, 288(3):669-699, 2005.

[22] P. Santos and A. Tadeu. Acoustic insulation provided by a single wall separating two contiguous tunnels via BEM. Journal of Sound and Vibration, 257(5):945-965, 2002.

[23] F. C. Sgard, N. Atalla, and J. Nicolas. A numerical model for the low frequency diffuse field sound transmission loss of double-wall sound barriers with elastic porous linings. Acoustical Society of America, 108(6):28652872,2000 .

[24] S. P. S. Maluski and B. M. Gibbs. Application of a finite-element model to low-frequency sound insulation in dwellings. Acoustical Society of America, 108(4):1741-1751, 2000. 
[25] D. Magliacano, M. Ouisse, A. Khelif, S. De Rosa, F. Franco, N. Atalla, and M. Collet. Computation of dispersion diagrams for periodic porous materials modeled as equivalent fluids. Mechanical Systems and Signal Processing, 142:106749, 2020.

[26] S. R. Gimeno. Study of the acoustic insulation through domestic windows. Master's thesis, Master's thesis, Escuela Politecnica Superior De Gandia, 2012.

[27] L. Kwapisz, A. Maurin, and P. Jakubowski. Numerical modelling of sound transmission through the window type partition. Vibrations in Physical Systems, 27, 2016.

[28] F. Løvholt, K. Norèn-Cosgriff, C. Madshus, and S. E. Ellingsen. Simulating low frequency sound transmission through walls and windows by a two-way coupled fluid structure interaction model. Journal of Sound and Vibration, 396:203-216, 2017.

[29] J. Mathys. Low-frequency noise and acoustical standards. Applied Acoustics, 40(3):185-199, 1993.

[30] C. Bedon and C. Amadio. Mechanical analysis and characterization of igus with different silicone sealed spacer connections-part 1: experiments. Glass Structures 6 Engineering, 5(3):301-325, 2020.

[31] C. Bedon and C. Amadio. Mechanical analysis and characterization of igus with different silicone sealed spacer connections-part 2: modelling. Glass Structures \& Engineering, 5(3):327-346, 2020.

[32] J.-L. Guyader and C. Lesueur. Acoustic transmission through orthotropic multilayered plates, part ii: Transmission loss. Journal of Sound and Vibration, 58(1):69-86, 1978.

[33] C. Soussi, M. Aucejo, W. Larbi, and J-F. DEÛ. Sound transmission through double-glazed window: Numerical and experimental analyses. In Proceedings of the 23rd International Congress on Acoustics, ICA 2019, integrating the 4th EAA Euroregio, Aachen, Germany, September 9-13, 2019.

[34] A. D. Pierce and R. T. Beyer. Acoustics: An Introduction to its Physical Principles and Applications. 1989 Edition. Acoustical Society of America, New York, 3rd edition, 1989. 
[35] W. Larbi, J-F. Deü, and R. Ohayon. A new finite element formulation for internal acoustic problems with dissipative walls. International journal for numerical methods in engineering, 68(3):381-399, 2006.

[36] W. Larbi, J-F. Deü, and R. Ohayon. Vibration of axisymmetric composite piezoelectric shells coupled with internal fluid. International Journal for Numerical Methods in Engineering, 71(12):1412-1435, 2007.

[37] W. Larbi, J.-F. Deü, and R. Ohayon. Vibroacoustic analysis of doublewall sandwich panels with viscoelastic core. Computers $\&$ Structures, 174:92-103, 2016.

[38] C.-H. Jeong. Diffuse sound field: challenges and misconceptions. Proceedings of Internoise 2016, pages 1015-1021, 2016.

[39] I. L. Vér and L. L. Beranek. Noise and Vibration Control Engineering. Principles and Applications. Wiley, 2nd edition, 2006.

[40] F. J. Fahy and P. Gardonio. Sound and Structural Vibration - Radiation, Transmission and Response. Elsevier, second edition edition, 2007.

[41] P. Guillaume, P. Verboven, and S. Vanlanduit. A poly-reference implementation of the least-squares complex frequency-domain estimator. In Proceedings of IMAC 21, the International Modal Analysis Conference, Kissimmee, Florida, USA, 2003.

[42] M. El-Kafafy, B. Peeters, T. De Troyer, and P. Guillaume. Polymax Plus estimator: better estimation of the modal parameters and their confidence bounds. In Proceedings of International Noise and Vibration conference ISMA 2014, Leuven, Belgium, 2014.

[43] C. Bedon, M. Fasan, and C. Amadio. Vibration analysis and dynamic characterization of structural glass elements with different restraints based on operational modal analysis. Buildings, 9(1):13, 2019.

[44] Free Field Technologies. Actran 17.1 User's Guide Volume 1 Installation, Operations, Theory and Utilities. 2017.

[45] ISO 338 : Bois de structure - Classes de résistance, 2016.

[46] ISO 14080 : Structures en bois - Bois lamellé collé et bois massif reconstitué - Exigence, 2013.

[47] R. J. Allemang. The modal assurance criterion- twenty years of use and abuse. Sound and vibration, 37(8):14-23, 2003. 
[48] C. Bedon. Issues on the vibration analysis of in-service laminated glass structures: analytical, experimental and numerical investigations on delaminated beams. Applied Sciences, 9(18):3928, 2019.

[49] C. Bedon. Diagnostic analysis and dynamic identification of a glass suspension footbridge via on-site vibration experiments and fe numerical modelling. Composite Structures, 216:366-378, 2019. 